
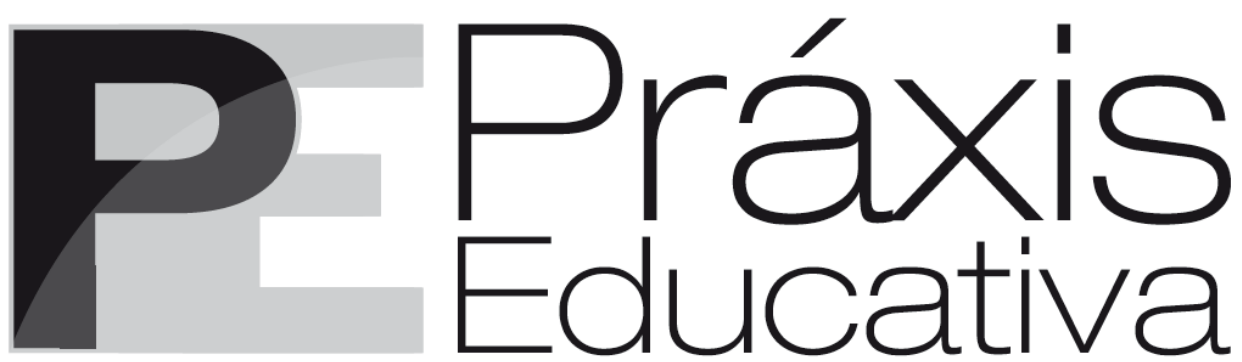

ISSN 1809-4031

eISSN 1809-4309

https://doi.org/10.5212/PraxEduc.v.15.15446.096

\title{
E1 progresivo avance de perspectivas conservadoras en la educación uruguaya en la última década
}

\section{The progressive advance of conservative perspectives in Uruguayan education in the last decade}

\section{O avanço progressivo das perspectivas conservadoras na educação uruguaia na última década}

\author{
Pablo Eduardo Martinis López ${ }^{*}$ \\ https://orcid.org/0000-0002-1210-0098
}

Resumen: Las elecciones presidenciales realizadas en Uruguay, en octubre y noviembre de 2019, definieron la finalización de un período de tres gobiernos sucesivos del partido de centro - izquierda Frente Amplio y la llegada al gobierno de una coalición de derechas liderada por el Partido Nacional. En el campo educativo, el desarrollo de una perspectiva conservadora, que está en la base de las propuestas educativas del nuevo gobierno, comenzó a desarrollarse en pleno período de auge de los gobiernos precedentes. El presente artículo pretende analizar cómo ese proceso de generación de una visión conservadora de la educación fue tomando forma en los últimos diez años a través, fundamentalmente, de la presentación de la llamada "educación pública de gestión privada" como una alternativa a la educación pública hegemonizada por el Estado. La perspectiva teórica que informa el conjunto del trabajo se ubica desde la lógica del análisis político del discurso y el abordaje metodológico se realiza a partir de la consideración de fuentes documentales.

Palabras claves: Educación. Conservadurismo. Uruguay.

\begin{abstract}
The presidential elections held in Uruguay in October and November 2019 defined the end of a period of three successive governments of the center-left party Frente Amplio and the arrival in government of a right-wing coalition led by the Partido Nacional. In education, the development of a conservative perspective, which is at the base of the educational proposals of the new government, began to develop in the height of the boom of the previous governments. The present article intends to analyze how this process of generating a conservative vision of education was taking shape in the last ten years through the presentation of the so-called "privately managed public education" as an alternative to public education. The theoretical perspective that informs the whole work is located from the logic of the political analysis of the discourse and the methodological approach is made from the consideration of documentary sources.
\end{abstract}

Keywords: Education. Conservatism. Uruguay.

\footnotetext{
* Profesor Titular en Régimen de Dedicación Total del Departamento de Pedagogía, Política y Sociedad (Facultad de Humanidades y Ciencias de la Educación - Universidad de la República, Uruguay). Doctor en Ciencias Sociales (FLACSO, Argentina). E-mail: <pablomartinis@gmail.com>.
}

Práxis Educativa, Ponta Grossa, v. 15, e2015446, p. 1-24, 2020 Disponível em: <https://www.revistas2.uepg.br/index.php/praxiseducativa> 
El progresivo avance de perspectivas conservadoras en la educación uruguaya en la última década

Resumo: As eleições presidenciais realizadas no Uruguai, em outubro e novembro de 2019, definiram o fim de um período de três governos sucessivos do partido de centro-esquerda Frente Amplio e a chegada ao governo de uma coalizão de direita liderada pelo Partido Nacional. No campo educacional, o desenvolvimento de uma perspectiva conservadora, que está na base das propostas educacionais do novo governo, começou a se desenvolver no auge do boom dos governos anteriores. Este artigo tem como objetivo analisar como esse processo de geração de uma visão conservadora da educação vem se formando nos últimos dez anos, fundamentalmente, pela apresentação da chamada "educação pública de gestão privada" como uma alternativa à educação pública que é hegemonizada pelo Estado. A perspectiva teórica que informa todo o trabalho está localizada a partir da lógica da análise política do discurso e a abordagem metodológica é feita a partir da consideração de fontes documentais.

Palavras-chave: Educação. Conservadorismo. Uruguai.

\section{Presentación}

El artículo que aquí se presenta pretende ofrecer una clave de lectura que dé cuenta del proceso a través del cual, en la última década, perspectivas conservadoras y neoliberales fueron ganando terreno en las construcciones sociales sobre educación presentes en Uruguay.

Desde un enfoque afectado por la perspectiva del análisis político del discurso (LACLAU; MOUFFE, 2004) y con una metodología de trabajo centrada en el análisis de fuentes documentales, el texto abarca el proceso mediante el cual se fue erosionando el carácter hegemónico de la educación pública en Uruguay.

$\mathrm{El}$ artículo se organiza en cinco apartados. En el primero, se hace referencia a la perspectiva teórica y metodológica que orienta el texto. En el segundo, se aborda el carácter hegemónico que históricamente ha tenido la educación pública en Uruguay. En tercer término, se abordan algunas características presentes en el desarrollo de la educación en Uruguay durante los gobiernos del Frente Amplio (2005 - 2019). En el cuarto, se aborda la construcción de la "educación púbica de gestión privada" como uno de los componentes claves que estructura el discurso conservador sobre la educación uruguaya. Finalmente, se presentan algunas breves conclusiones como apuntes para la continuidad de trabajos de investigación.

\section{Breves notas conceptuales}

El texto que aquí se presenta se ubica en el marco de una línea de investigación ocupada en el análisis de las formas que asume la disputa en torno al carácter público de la educación en Uruguay en la última década. Interesa particularmente apreciar cómo un valor profundamente asentado en la sociedad uruguaya, el de la educación pública, comenzó a ser socavado por medio de producciones discursivas que enfatizaban la crisis de esta educación por su supuesta incapacidad de dar respuesta a la "brecha educativa" instalada en la sociedad uruguaya.

El enfoque teórico general, que orienta la investigación, se sostiene en la producción sobre lo social y los procesos de construcción hegemónica abordados desde la perspectiva del análisis político del discurso (LACLAU; MOUFFE, 2004). Por ello, cuando hacemos referencia a producciones discursivas no estamos sugiriendo meramente enunciados lingüísticos sino

\footnotetext{
${ }^{1}$ La línea de investigación se denomina "Disputas en torno al carácter público de la educación en Uruguay". Se encuentra radicada en el Grupo de Estudios en Políticas y Prácticas Educativas del Departamento de Pedagogía, Política y Sociedad (FHCE - UdelaR). <https://geppred.uy/>.

${ }^{2}$ Con este concepto se hace referencia a las grandes diferencias de aprendizajes que se presentan en las evaluaciones estandarizadas a favor de los sectores socioeconómicamente mejor ubicados en detrimento de los más pobres.
}

Práxis Educativa, Ponta Grossa, v. 15, e2015446, p. 1-24, 2020 Disponível em: <https://www.revistas2.uepg.br/index.php/praxiseducativa> 
procesos sociales de construcción de significaciones, que pugnan por hegemonizar los sentidos sobre lo educativo y que circulan socialmente.

Nos interesa recuperar de esta perspectiva teórica una noción de sociedad entendida como estructura incompleta, en última instancia imposible (LACLAU, 1993), nunca plenamente suturada, habitada por el conflicto y en permanente disputa entre diversas posiciones que pretenden construir hegemonía.

Para la comprensión de este enfoque sobre lo social, resulta crucial integrar la distinción en lo político y la política que introduce Mouffe (2009). En palabras de la propia autora:

Concibo "lo político" como la dimensión del antagonismo que considero constitutiva de las sociedades humanas, mientras que entiendo a "la política" como el conjunto de prácticas e instituciones a través de las cuales se crea un determinado orden, organizando la coexistencia humana en el contexto de la conflictividad derivada de lo político (MOUFFE, 2009, p. 16).

Esta distinción nos permite, por una parte, apreciar en un nivel máximo de abstracción al antagonismo con su inherente conflictividad, como elemento constitutivo de la conformación y existencia de las sociedades humanas. El conflicto tendría una dimensión inerradicable y se expresaría en el nivel de la práctica a través de las permanentes disputas por la hegemonía propias del ámbito de la política. Aquí, las prácticas sociales tendientes a la creación y legitimación de diversos órdenes sociales pugnan por imponerse y ubicar sus significaciones como válidas.

Está claro que ninguno de estos procesos se desenvuelve de modo independiente con respecto a la base económica y material de una sociedad. Precisamente, las formas en que se configura son expresión de relaciones de fuerza profundamente materiales. Del mismo modo, los efectos de estas prácticas hegemónicas son también profundamente materiales en la medida que estructuran órdenes sociales más, o menos, igualitarios.

Por lo señalado precedentemente, para nuestro enfoque de investigación es particularmente relevante asumir que:

Cualquier orden es siempre la expresión de una determinada configuración de relaciones de poder. Lo que en un determinado momento se acepta como el orden "natural", junto con el sentido común que lo acompaña, es el resultado de prácticas hegemónicas sedimentadas. Nunca es la manifestación de una objetividad más profunda, ajena a las prácticas que le dieron origen. Por lo tanto, todo orden es susceptible de ser desafiado por prácticas contrahegemónicas que intenten desarticularlo en un esfuerzo por instalar otra forma de hegemonía" (MOUFFE, 2014, p. 22).

En definitiva a nuestro enfoque, recuperando los componentes centrales que aporta el análisis político del discurso, le interesa especialmente apreciar las formas en que se estructuran las disputas por fijar sentidos en torno a lo educativo en la última década. Observar estos procesos tiene, para nosotros, una importancia crucial en términos académicos y políticos, ya que en esta década se fue produciendo paulatinamente un desmontaje de la concepción progresista presentada a la sociedad uruguaya en los gobiernos del Frente Amplio (2005 - 2019).

Presentar una clave de lectura acerca de cómo estos procesos se fueron desarrollando es el objetivo central de este artículo. Para ello, priorizamos un estilo de trabajo que busca exponer y analizar procesos históricos y sociales recurriendo al análisis de fuentes documentales. Optamos por una forma de trabajo en la cual el análisis se articula con las referencias empíricas en un proceso que pretende ser integral.

En este sentido, tomamos distancia de la concepción de Howarth (2005) según la cual sería 
posible aplicar metodológicamente el análisis político del discurso en las investigaciones sociales mediante lo que el autor denomina el "método de la articulación". Asumimos las críticas que Saur (2008) introduce ante la idea de aplicación de la teoría sobre el referente empírico. Si bien el autor entiende que en todo trabajo de indagación es posible ubicar tanto elementos novedosos como otros que tienden a la simple reproducción de lo pre-existente, es muy claro al señalar que:

[...] no todas las investigaciones son iguales, ya que algunas se acercan más a la repetición que a lo original, a lo reiterativo que a lo novedoso, a lo burocrático que a lo disruptivo. Aquí es donde cobra importancia por la limitación que impone la noción de aplicación, como dijimos, como metáfora que muestra una forma de intervención sobre los problemas en estudio, caracterizada por la sobreimpresión de la teoría sobre los referentes empíricos, condicionando fuertemente los resultados y acercándose riesgosamente a los modelos nomológicos de explicación (SAUR, 2008, p. 10).

Nuestra intención, al utilizar herramientas conceptuales que el análisis político del discurso provee a los estudios sociales, es evitar ese fenómeno de "sobreimpresión" de la teoría sobre la empírea a la que refiere Saur. Más nos interesa un esfuerzo de producción de conocimiento que "ponga en tensión el saber teórico, el referente empírico y el lugar del científico" (SAUR, 2008, p. 12).

Por esto, a lo largo de los diversos apartados en los que está organizado el presente texto, intentaremos mostrar algunos núcleos de sentidos que entendemos claves para dar cuenta de cómo se ha ido produciendo un progresivo avance de perspectivas neoconservadoras en la educación uruguaya en la última década. Ello supone dar cuenta de los modos a través de los cuales se ha puesto en cuestión la tradicional posición hegemónica de la educación pública, así como explorar las construcciones discursivas desde las que se ha ubicado a la "educación pública de gestión privada" como alternativa ante lo público.

La comprensión de esta situación no puede darse por fuera de una visualización de los procesos de privatización educativa que han ganado terreno a nivel global desde fines del siglo pasado. Como bien señala Hall (1987), la ofensiva desatada en Gran Bretaña en la década de 1980 por el gobierno conservador de Margaret Thatcher, se orientó en el sentido de

Desmantelar una época completa, invertir sus orientaciones fundamentales, desorganizarla e inaugurar una nueva. La política de privatizaciones pretende erosionar el principio mismo del Estado de bienestar (HALL, 1987, p. 29).

Ciertamente, se trató de un proyecto exitoso que permitió el desmontaje de treinta años de políticas de bienestar y estableció las bases para una nueva hegemonía económica, social y educativa centrada en los principios neoliberales. Esta onda recorrió también América Latina y estuvo en la base de las reformas educativas que en la década de 1990 recorrieron el continente.

El amplio desarrollo de gobiernos progresistas en la primera década y media del nuevo siglo en nuestro continente no tuvo la fuerza como para fundar una nueva hegemonía. De hecho, en varios países, pese a la sucesión de gobiernos definidos como de centro izquierda, se convivió con reformas fuertemente afectadas por el neoliberalismo. El caso más claro de esta situación seguramente sea el chileno (BELLEI, 2015), pero una mirada al conjunto del continente permitirá apreciar diversos niveles de afectación de las políticas progresistas por parte de sentidos neoliberales (LEHER, 2009; VIOR, 2018).

Por esto, como desarrollaremos en el cuarto apartado del presente texto, no es de sorprender que el declive de los gobiernos progresistas en la región nos encuentre con diversas formas de promoción de la privatización educativa en los diferentes países (VERGER et al., 2017). 
Desde el punto de vista del enfoque conceptual general que orienta nuestro trabajo de investigación, asumimos la distinción entre procesos de privatización exógenos y endógenos que proponen Ball y Youdell (2008). Para estos autores, la privatización exógena se identifica en términos generales con la tendencia a expandir el sector privado, aumentando su influencia en el conjunto del sistema educativo a través, por ejemplo, de la producción de alianzas del sector público con el privado. Por otra parte, la privatización endógena supone la asunción de principios propios de la lógica de la empresa privada en la educación pública. Entendemos que para comprender cabalmente los procesos de privatización educativa es necesario tener en cuenta ambas dimensiones $y$, particularmente, las formas en que se hibridan en las prácticas de la política educativa.

En el caso concreto de nuestro estudio del caso uruguayo, la mirada sobre las disputas por la construcción de posiciones hegemónicas entre ámbitos públicos y privados necesariamente ha de tomar nota sobre las formas específicas en que se entrelazan estas dimensiones de la privatización educativa. Por ello, nuestro análisis intentará trascender la lógica de la clasificación taxonómica en beneficio de aportar claves de lectura que muestren la complejidad de los procesos sociales y educativos.

\section{Hegemonía del sistema educativo público en Uruguay y estatus de la educación privada}

Desde que en el último tercio del siglo XIX se estableció un sistema educativo con carácter nacional en Uruguay, la educación pública ha tenido un carácter hegemónico en el país.

El Decreto - Ley de Educación Común, sancionado el 23 de setiembre de 1877, definió a la educación como laica, gratuita y obligatoria, colocando las bases de un sistema educativo que se encontraría plenamente constituido ya en las primeras décadas del siglo XX. Así, se pusieron las bases para la construcción de un sistema de instrucción público centralizado y estatal, tomado la categoría definida por Puiggrós (1990).

Ello no significó la eliminación de la educación privada, pero sí su ubicación en una posición subsidiaria y sujeta al papel rector de la educación pública. De hecho, la existencia de la educación privada en el Uruguay está garantizada por normas de rango constitucional. En la Constitución vigente (1967) la temática se aborda en el artículo 68, el cual establece la libertad de enseñanza en tanto "Todo padre o tutor tiene derecho a elegir, para la enseñanza de sus hijos o pupilos, los maestros o instituciones que desee"3. Por otra parte, el artículo 69 establece que "Las instituciones de enseñanza privada y las culturales de la misma naturaleza estarán exoneradas de impuestos nacionales y municipales, como subvención por sus servicios"4.

Estos preceptos constitucionales tienen una larga tradición en el país. La Constitución de 1942 (artículo 60), ya establecía las exoneraciones impositivas mencionadas. De este modo, puede señalarse que, tradicionalmente, en Uruguay ha existido un sistema de educación privada. Este sistema ha oscilado históricamente en un rango entre el 15\% y el $20 \%$ de la matrícula total. Como ejemplo de lo señalado, podemos establecer que, tomando algunos momentos de la serie estadística presentada por MEC (2014), la relación público privado se presentó de la siguiente forma en el nivel de educación primaria.

\footnotetext{
3 Tomado de Uruguay (1967). Constitución de 1967 con las modificaciones plebiscitadas el 26 de noviembre de 1989, el 26 de noviembre de 1994, el 8 de diciembre de 1996 y el 31 de octubre de 2004. Recuperado de https://www.impo.com.uy/bases/constitucion/1967-1967

4 Ídem.
}

Práxis Educativa, Ponta Grossa, v. 15, e2015446, p. 1-24, 2020 Disponível em: < https://www.revistas2.uepg.br/index.php/praxiseducativa> 
El progresivo avance de perspectivas conservadoras en la educación uruguaya en la última década

Tabla 1 - Tasa de participación de la matrícula de Educación Primaria según forma de administración por años seleccionados

\begin{tabular}{c|c|c|c}
\hline Año & $\begin{array}{c}\text { Matrícula Primaria } \\
\text { pública }\end{array}$ & $\begin{array}{c}\text { Matrícula Primaria } \\
\text { privada }\end{array}$ & Total \\
\hline 1900 & 72,2 & 29,8 & $100 \%$ \\
\hline 1930 & 88,3 & 11,7 & $100 \%$ \\
\hline 1960 & 80 & 20 & $100 \%$ \\
\hline 1990 & 83,8 & 16,2 & $100 \%$ \\
\hline 2012 & 83,4 & 16,6 & $100 \%$ \\
\hline
\end{tabular}

Fuente: elaboración propia en base a datos de MEC (2014).

Complementariamente, el último dato disponible establece que esta relación se ubicó en un $83 \%$ de matrícula en la educación púbica y un $17 \%$ en la privada, sobre un total de 292.787 alumnos, en el año 2019.

Es importante hacer referencia a estos datos estadísticos, ya que muestran el peso en términos cuantitativos de la matrícula de la educación pública en el conjunto de los alumnos que asisten al nivel educativo Primario. La situación no es significativamente diversa en la Enseñanza Media, ya que en la misma la relación se establece en el año 2019 en un 88,8\% de alumnos matriculados en la educación pública y un 11,2 en la privada, sobre un total de 358.362 alumnos.

En síntesis, el sistema educativo uruguayo presenta una matrícula que históricamente se ha concentrado fuertemente en la educación pública. Sin desmedro de esta situación, es relevante destacar que normas de carácter constitucional aseguran, desde las primeras décadas del siglo XX, la existencia de la educación privada, tanto a nivel del reconocimiento de la libertad de los padres para elegir esa modalidad educativa, como a nivel de la existencia de exoneraciones fiscales dirigidas a favorecer su ecuación económica. Estos reaseguros hacia la educación privada, incluidos en la Constitución de la República, dan cuenta de avances conservadores en el marco de históricas disputas con el Estado por la definición del carácter de la educación nacional.

\section{Políticas educativas progresistas (2005 - 2019). Logros y carencias}

El carácter hegemónico y rector de la educación pública en el país tuvo un nuevo impulso durante los años en que se desarrolló la llamada era progresista (GARCÉ; YAFFÉ, 2005). Esta se define por la existencia consecutiva de tres gobiernos de la coalición de centro - izquierda Frente Amplio en el país, los cuales abarcaron el período comprendido entre los años 2005 y 2019. Es posible señalar que, durante este período, se condensaron fuertemente un conjunto de prácticas hegemónicas articuladas en torno a la centralidad de la educación pública en la sociedad uruguaya. Estas prácticas, sostenidas en una más que centenaria tradición pedagógica nacional, tuvieron su expresión en la Ley General de Educación No 18437 aprobada en el año 2008 (MEC, 2008). Si bien no es aún posible afirmar esto categóricamente, es probable que los avances en la consolidación de una hegemonía educativa basada en la centralidad de la educación mediante esta Ley, hayan configurado una señal de alarma para una reactivación de sectores conservadores. De hecho, éste

5 Tomado del Observatorio de la Educación de la ANEP. Referencia: http://observatorio.anep.edu.uy/index.php/matricula

Práxis Educativa, Ponta Grossa, v. 15, e2015446, p. 1-24, 2020 Disponível em: < https://www.revistas2.uepg.br/index.php/praxiseducativa> 
es un fenómeno que, en términos generales, puede apreciarse en diversos países de América Latina como reacción a la consolidación de gobiernos definidos genéricamente como "progresistas".

La mencionada Ley, en su artículo primero, señala a la educación como un derecho humano fundamental y como un bien público y social, estableciendo que "el Estado garantizará y promoverá una educación de calidad para todos sus habitantes, a lo largo de toda la vida, facilitando la continuidad educativa" (MEC, 2008, p. 11). A este respecto, en el artículo 12 se define que la política educativa se organizará con "el objetivo fundamental, que todos los habitantes del país logren aprendizajes de calidad, a lo largo de toda la vida y en todo el territorio nacional, a través de acciones educativas desarrolladas y promovidas por el Estado, tanto de carácter formal como no formal” (MEC, 2008, p. 13).

Desde el punto de vista organizativo, en el artículo 49 la Ley otorga un lugar central en las estructura de gobierno del sistema educativo al denominado "Sistema Nacional de Educación Pública" (SNEP), el cual es integrado por todos los entes vinculados a la educación en la arquitectura organizacional del sistema educativo uruguayo: Ministerio de Educación y Cultura, Administración Nacional de Educación Pública y Universidad de la República (URUGUAY, 2008, p. 22). En el artículo 50, se establece que este SNEP es coordinado por una "Comisión Coordinadora del Sistema Nacional de Educación Pública" integrada por las principales autoridades de los organismos que lo conforman (URUGUAY, 2008, p. 22). En el artículo 108 de la Ley se establece que a esta Comisión le compete, entre otras responsabilidades, la planificación de la educación pública (URUGUAY, 2008, p. 40). A lo largo de toda la Ley, queda claramente establecido el carácter rector de la educación pública en el conjunto de la educación uruguaya, así como el carácter subsidiario de la educación privada.

De este modo, la Ley se constituye en expresión de una práctica hegemónica sedimentada en torno a la educación pública. Apreciando los procesos que se darán en el país en ladeada siguiente, es posible hipotetizar, como ya hemos señalado, acerca de que éste haya sido precisamente el hecho ante el cual los sectores conservadores asumieran plenamente la necesidad de avanzar en el desarrollo de una posición contrahegemónica.

En lo que hace al contenido de las políticas desarrolladas durante los tres períodos de gobierno por parte del Frente Amplio, existe una amplia bibliografía que se ha dedicado a su análisis (BENTANCUR; BUSQUETS, 2019; MARTINIS, 2019a; BORDOLI; et al., 2017; MARTINIS; FALKIN, 2017; MARTINIS, 2016; MANCEBO, 2014, entre otros).

Sintéticamente, es posible plantear que la noción de derecho universal a la educación se ubicó como uno de los ejes centrales en la fundamentación de las políticas desarrolladas. La inexistencia de una definición clara sobre esta noción en el campo progresista en Uruguay, llevó al establecimiento de disputas en torno al sentido de este concepto en el marco de implementación de las políticas educativas (MARTINIS; FALKIN, 2017). Esto se puede apreciar en la conformación de dos líneas discursivas que, si bien no se constituyen como antagónicas, presentan importantes matices. Las dos discursividades mencionadas podrían ser presentadas del siguiente modo: a) una que expresa continuidad conceptual con las políticas de equidad que tuvieron su apogeo en América Latina en la década de 1990, sustentándose fundamentalmente en una apelación a la lógica de focalización social y cultural en la implementación de las políticas educativas (MARTINIS, 2016); b) otra en la que se expresan perspectivas democratizadoras, ocupando en ellas un lugar central el significante igualdad, como es propuesto por Ranciére (2003), presentes como fragmentos de discursos que apelan a la concepción de la educación desde una entonación universalista. En este segundo caso, se impulsaron programas educativos que tendieron a organizarse, no desde lógicas de focalización, sino pretendiendo interpelar al conjunto del sistema educativo. Un ejemplo de esto lo constituye el desarrollo del Programa "Maestros Comunitarios" 
El progresivo avance de perspectivas conservadoras en la educación uruguaya en la última década

a partir del año 2005 (BORDOLI, 2019).

Esta ausencia de un discurso que diera identidad propia a las políticas educativas y sociales genéricamente definidas como progresistas, propició espacios para que pudieran circular, sin demasiado conflicto y con amplias posibilidades de generar un relato creíble, algunas perspectivas conservadoras, al influjo de un proceso ampliamente presente en el conjunto de la región sudamericana (CTERA, 2016; ADRIÃO; PERONI, 2008; PERONI, 2013; PERONI et al., 2018). Aquí ubicamos un elemento clave para entender el impulso a procesos de construcción contrahegemónica impulsados por los sectores políticos, sociales y educativos conservadores en Uruguay.

A su vez, complementariamente, estas construcciones de sentido de carácter conservador tomaron fuerza como prácticas de oposición ante el avance producido en el período progresista en la llamada "agenda social" (matrimonio igualitario, interrupción voluntaria del embarazo, y legislación para atender la situación de las personas trans ${ }^{6}$ ).

Un significante permanentemente presente en las formulaciones de las perspectivas conservadoras, y de las derechas en términos generales, es el de la denuncia de la situación de crisis en las que se encontraría la educación uruguaya ante el fracaso de las políticas progresistas. Esta apelación a la crisis tuvo abundante circulación a nivel político, inclusive con algunas adhesiones de actores de diversas fuerzas progresistas, y también una generosa difusión por parte de los medios de comunicación más importantes del país. El argumento central, esgrimido para defender la idea de la existencia de una crisis educativa, tiene que ver con el señalamiento de los bajos niveles de egreso que presenta el país a nivel de la Enseñanza Media. Esto fue particularmente tematizado en la noción de "brecha de aprendizajes" vinculada a los resultados educativos de los sectores más pobres.

Resulta conveniente detenerse en este argumento, por el peso determinante que ha tenido en la generación de un discurso con amplia aceptación social acerca de la eventual crisis de la educación uruguaya.

En la siguiente tabla puede apreciarse el porcentaje de personas mayores de 17 años que han culminado la Enseñanza Media en Uruguay, presentadas por intervalos de edades.

Tabla 2 - Porcentaje de personas mayores de 17 años que completaron el segundo ciclo de Enseñanza Media

\begin{tabular}{|c|c|c|c|c|c|c|c|c|c|c|c|c|c|c|}
\hline Edades & 2006 & 2007 & 2008 & 2009 & 2010 & 2011 & 2012 & 2013 & 2014 & 2015 & 2016 & 2017 & 2018 & 2019 \\
\hline 18 a 20 & 23,9 & 25,8 & 27,9 & 26,0 & 25,3 & 28,2 & 28,4 & 27,8 & 28,5 & 28,9 & 29,4 & 31,1 & 33,8 & 34,6 \\
\hline 21 a 23 & 35,4 & 34,8 & 36,1 & 35,2 & 35,6 & 39,9 & 38,3 & 39,0 & 39,5 & 39,6 & 39,2 & 41,8 & 43,4 & 43,3 \\
\hline 24 a 29 & 33,8 & 35,1 & 36,9 & 37,5 & 34,9 & 40,7 & 40,6 & 39,3 & 40,5 & 41,8 & 42,1 & 42,7 & 44,9 & 44,7 \\
\hline 30 o más & 23,9 & 24,8 & 25,3 & 26,1 & 25,5 & 26,5 & 27,7 & 27,6 & 28,7 & 28,6 & 28,6 & 29,9 & 30,0 & 31,3 \\
\hline
\end{tabular}

Fuente: Tomado de ANEP, Dirección Sectorial de Planificación Educativa ${ }^{7}$

Las cifras presentadas abarcan la casi totalidad del período definido como "era progresista".

\footnotetext{
${ }^{6}$ Se hace referencia a la Ley Integral para Personas Trans No 19684, aprobada en 2018 y que establece medidas de discriminación positiva a favor de la población trans.

${ }^{7}$ Información disponible en: http://observatorio.anep.edu.uy/index.php/resultados-logros
} 
Como puede observarse, si bien los avances pueden ser reportados como escasos, no es posible plantear que la situación ha empeorado en el período referido.

Si los datos consignados en la tabla se ponen en diálogo con los vinculados a los niveles de escolarización de los jóvenes uruguayos, el debate toma un cariz interesante. Efectivamente, basándonos en información del Sistema de Información de tendencias educativas en América Latina, podemos apreciar que, para el año 2015, la tasa neta de escolarización en Enseñanza Media en Uruguay era del 78,43\%, mientras que en Argentina, era del 86,63. La diferencia entre valores es ciertamente modesta si la comparamos con los niveles de egreso de Enseñanza Media en Argentina, donde cerca del $70 \%$ de los jóvenes de entre 20 y 22 años concluyen la Enseñanza Media ${ }^{8}$.

Si bien el objetivo de este artículo no es discutir la idea de la crisis de la educación en Uruguay, nos ha parecido interesante aportar estos datos comparativos con un país con el que se tiene una gran similitud histórica y cultural como Argentina, a los efectos de colocar en discusión aquel enunciado. El problema de Uruguay no parece estar ubicado en los niveles de acceso al sistema, sino en los de egreso de éste. Es posible que esto exprese el peso que tienen algunas formas tradicionales de funcionamiento de la enseñanza y los medios de evaluación de los aprendizajes, más que estarnos dando la pauta de una situación de crisis radical. Es posible sostener que el enfrentamiento de la situación puede producirse mediante ajustes en las formas de enseñar y evaluar, estando esto muy lejos del cariz de las medidas que sería necesario tomar ante una situación de crisis que diera cuenta de un fracaso absoluto de la política educativa.

No obstante, el relato acerca de la crisis ha sido exitoso en la construcción de agenda educativa en el país. Explicar cabalmente los modos en que dicho relato ha podido ocupar esa posición excede los alcances de este artículo. Sí nos parece importante resaltar que éste ha sido uno de los factores que ha incidido en la opinión pública en cuanto a la generación de un sentimiento de necesidad de producir un cambio de fuerza política en el gobierno. Desde la mirada afectada por el análisis político del discurso que nutre conceptualmente nuestro enfoque, nos encontramos frente a complejos procesos de dessedimentación de prácticas hegemónicas y de construcción de nuevas posiciones hegemónicas. Las disputas en torno al sentido del significante "educación pública" y a su relación con los ámbitos privados se ubican en el centro de estos procesos políticos.

\section{La educación pública de gestión privada como alternativa de cambio en la educación uruguaya}

\section{La privatización "latente" en Uruguay}

En línea con lo recién planteado, algunas investigaciones han señalado que, en la última década, se vendría desarrollando en la educación uruguaya un proceso de expansión privatizadora, en consonancia con la situación en curso en buena parte del continente. En el estudio realizado por Verger, Moschetti y Fontdevila (2017), se distinguen siete formas de caracterizar la privatización educativa en América Latina. Solamente una de ellas es apreciada como de reversión de procesos privatizadores (es el caso de Bolivia). En las seis restantes se valoran diversas formas de promoción de la privatización en la educación. Las formas en que se denomina a estas seis modalidades son las que se presentan en la tabla 3.

\footnotetext{
${ }^{8}$ Datos tomados de https://www.siteal.iiep.unesco.org
} 
El progresivo avance de perspectivas conservadoras en la educación uruguaya en la última década

Tabla 3 - Modalidades de privatización educativa en América Latina

\begin{tabular}{|l|c|}
\hline \multicolumn{1}{|c|}{ Modalidad } & $\begin{array}{c}\text { País o países en los que se presenta } \\
\text { esta modalidad }\end{array}$ \\
\hline $\begin{array}{l}\text { Privatización educativa como parte de la reforma } \\
\text { estructural del Estado }\end{array}$ & Chile \\
\hline Privatización como reforma incremental & Brasil, Colombia \\
\hline $\begin{array}{l}\text { Privatización 'por defecto' y emergencia de } \\
\text { escuelas privadas de bajo costo } \\
\text { Alianzas público-privadas históricas }\end{array}$ & Jamaica, Perú, República Dominicana. \\
\hline Privatización por vía del desastre & \begin{tabular}{c} 
Argentina y República Dominicana \\
\hline Privatización latente
\end{tabular} \\
\hline
\end{tabular}

Fuente: Elaboración propia a partir de información de Verger, Moschetti y Fontdevila (2017).

Excede los alcances del presente artículo detenernos en las características que, para los autores mencionados, asume cada una de las modalidades de privatización referidas. Nos detendremos en señalar lo que refiere específicamente al caso de Uruguay. Los autores señalan:

\begin{abstract}
Uruguay ha conocido históricamente un desarrollo muy limitado del sector privado, aunque durante las últimas décadas se observan síntomas de un cierto impulso a lógicas pro-mercado. El rol marginal del sector privado se atribuye históricamente a la temprana separación Iglesia-Estado, mientras que su limitado crecimiento durante las últimas décadas se explica por una conjunción de mecanismos ligados sobre todo a la tradición centralizadora, pluralista y gradualista del sistema político uruguayo. No obstante, en los últimos años, se detecta un giro en el plano discursivo y una incipiente cooperación público-privada en forma de iniciativas experimentales, o de propuestas legislativas tendientes a favorecer dicha cooperación, que han acabado permeando en casi todo el espectro político. Así mismo, otras leyes de carácter extra-educativo han contribuido a crear un clima económico propicio a la iniciativa privada en materia de provisión de todo tipo de servicios sociales, incluyendo los educativos (VERGER et al., 2017, p. 7).
\end{abstract}

La descripción planteada en la cita precedente señala una serie de elementos que se articulan con la lógica que guía la escritura del presente artículo. Por una parte, se establecen claves de lectura que justifican el escaso desarrollo de la educación privada en el país. Entre estos se señalan, con indudable acierto, aspectos vinculados a la cultura política del país y a la separación entre Iglesia y Estado. Sin desmedro de esto, debe señalarse también, que el escaso desarrollo de la educación privada no ha sido obstáculo para que en diversas circunstancias históricas se lograra introducir en la Constitución nacional elementos de resguardo de esas expresiones educativas.

Por otra parte, los autores dan cuenta de algunos procesos que estarían mostrando novedades en cuanto al lugar que la consideración de la educación privada ocupa en la sociedad uruguaya. Estos movimientos, que estarían promoviendo procesos de privatización, tienen que ver con cambios a nivel discursivo, innovaciones legislativas tendientes a favorecer el direccionamiento de fondos a instituciones privadas, entre otros fenómenos. Es de señalar que estos movimientos se producen en plena "era progresista", alcanzando también a involucrar a sectores progresistas, como sugieren los investigadores citados.

Práxis Educativa, Ponta Grossa, v. 15, e2015446, p. 1-24, 2020 Disponível em: < https://www.revistas2.uepg.br/index.php/praxiseducativa> 
En un trabajo de investigación posterior (BORDOLI et al., 2017; MOSCHETTI et al., 2019), han tomado la hipótesis de la privatización latente como material de trabajo, rastreando algunas de las acciones que la estarían promoviendo. Básicamente, se ubican tres mecanismos que han funcionado promoviendo niveles de privatización en la educación uruguaya en las últimas décadas.

Uno de ellos abarca el área de la educación no formal y tiene que ver con los convenios entre Estado y organizaciones de la sociedad civil (OSC) que se vienen suscribiendo desde 1990. Estos convenios suponen la transposición de recursos por parte del Estado para que diversas OSC desarrollen acciones educativas y sociales con niños y adolescentes fuera de los marcos de la educación formal. Estamos aquí ante formas de colaboración público - privado en las que el Estado delega en actores privados la ejecución de porciones de las políticas públicas.

Otro procedimiento tiene que ver con la celebración de acuerdos entre Estado y empresas para el desarrollo de infraestructura educativa bajo la modalidad conocida como participación público privada ( PPP $^{9}$ ). Esta modalidad nos remite directamente a una de las formas prototípicas de privatización exógena definidas por Ball y Youdell (2008).

Finalmente, una tercera forma de promoción de la privatización, en nuestra opinión la fundamental, se ubica en la generación por vía legal del instrumento de las "Donaciones Especiales". Debido al peso que esta herramienta ha tenido en la promoción de procesos de privatización educativa, y en la producción de discurso que la promueve, es que nos detendremos particularmente en su consideración.

Antes de entrar a analizar particularmente esta tercera modalidad, entendemos necesario señalar cómo en el caso uruguayo es posible apreciar la existencia de manifestaciones, tanto de procesos de privatización exógena, como endógena.

Como señalamos en el primer apartado de este artículo, apreciamos que observar el carácter híbrido de las manifestaciones de la privatización educativa en Uruguay resulta de particular interés. La transferencia de recursos estatales a través de convenios a organizaciones de la sociedad civil, la suscripción de acuerdos de Participación Público Privada y el establecimiento de mecanismos para que empresas privadas puedan ser donantes de instituciones educativas, constituyen diversas facetas de la privatización educativa. Comprenderlas en sus interrelaciones, y en los efectos que producen, resulta fundamental para una comprensión cabal del caso uruguayo

A los efectos de facilitar la comprensión de la modalidad de "Donaciones Especiales", es necesario señalar que se estableció en la Ley de Reforma Tributaria No. 18083. Esta Ley instituyó un procedimiento de exoneraciones impositivas a las empresas privadas que apoyen proyectos de instituciones de enseñanza, investigación, salud y trabajo con la niñez. En su artículo 78 la Ley establece que las empresas que realicen estas donaciones recibirían exoneraciones fiscales por el $75 \%$ del monto donado. También se establece que el restante $25 \%$ podrá computarse como "gasto de la empresa", por lo cual también le corresponde un beneficio parcial de exoneración fiscal. Con este ajuste, el total de la exoneración fiscal se ubica en el 81,25\% de lo efectivamente donado.

Diversas leyes aprobadas posteriormente han introducido ajustes al sistema de donaciones especiales. Se trata de las leyes18.834 (2012), 19149 (2014), 19438 (2018) y $19670(2018)^{10}$.

\footnotetext{
9 Para profundizar acerca de los alcances de esta modalidad en Uruguay puede visitarse https://www.mef.gub.uy/583/2/areas/participacion-publico-privada---uruguay.html

10 Todas ellas disponibles para su consulta en www.parlamento.gub.uy
} 
Un elemento que interesa destacar es que las entidades destinatarias de las donaciones a realizar en el marco de este instrumento pueden ser tanto instituciones públicas como privadas. De hecho, en el primer año en que el mecanismo se hizo efectivo (2010), sobre un total de 31,8 millones de pesos uruguayos donados, 31,3 millones fueron destinados a la educación pública ${ }^{11}$. Esto significa que el $98,4 \%$ de las donaciones fueron a parar a las arcas públicas. Inversamente, si tomamos en cuenta el último dato disponible, correspondiente al año 2018, de un total de 155,9 millones de pesos donados, solamente 7,2 millones fueron destinados a instituciones públicas. Ello implica que el 4,8\% de lo donado fue dirigido hacia el ámbito público. Es de notar que en el período reseñado se produjo de hecho una notable transferencia de recursos hacia el sector privado, motivado no solamente por el aumento de los montos donados sino también por la radical reversión de la tendencia de relación entre público / privado que se presentaba al comienzo del proceso.

A los efectos de tener presente el incremento real de las donaciones producidas por las empresas privadas téngase en cuenta que el porcentaje de incremento de éstas, entre 2010 y 2018 , es del 490\%, mientras que la inflación en el mismo período fue del 188,6\% y el incremento del valor de dólar se ubicó en el $63 \%{ }^{12}$.

Por otra parte, es necesario tomar en cuenta que, la modalidad de donaciones especiales habilita la realización de aportes a empresas privadas hacia instituciones educativas, pudiendo deducir del total de lo donado un $81,25 \%$ por la vía de exoneraciones fiscales. Se trata, por tanto, de donaciones que, si bien son direccionadas por empresas privadas, son básicamente pagadas por el estado uruguayo. En otros términos, nos encontramos frente a una modalidad indirecta de asignación de recursos públicos a entidades privadas (BORDOLI et al., 2017).

En definitiva, nos interesa llamar la atención acerca de que un conjunto de empresas privadas ha realizado, en dicho período, una formidable movilización de recursos presupuestales desde arcas estatales hacia el ámbito privado, pagando por ello un costo relativamente bajo.

Nuestra hipótesis de trabajo sostiene que han existido formas de coordinación entre estas empresas privadas a los efectos de dirigir cuantiosos recursos hacia algunas instituciones que han cumplido una función ideológica clave, habilitando la producción de un discurso acerca de las bondades de una educación gestionada por actores privados con respecto a la educación pública.

Este tipo de instituciones, autodenominadas como "púbicas de gestión privada" han sido muy eficaces en captar donaciones provenientes de esta modalidad y han participado de redes más amplias, que pretenden disputar las formas en que se concibe el carácter público de la educación en el Uruguay. Así, se generó una fuente de financiamiento privilegiada para la materialización de experiencias educativas que sustentan el discurso contrahegemónico centrado en la idea de la superioridad de la gestión privada sobre la pública.

\section{La educación "pública de gestión privada". El caso del Liceo Impulso}

Nuestro trabajo de investigación nos ha permitido identificar la institución que ha ocupado el lugar modélico en este proceso de construcción contrahegemónica. Se trata del Liceo "Impulso".

En un trabajo anterior (MARTINIS, 2019b) nos detuvimos en una caracterización de esta

\footnotetext{
11 Toda la información presentada en este párrafo ha sido tomada de MEF (2018).

${ }^{12}$ Los cálculos de incremento de la inflación y del valor del dólar se han realizado a partir de información disponible en el sitio del Banco Central de Uruguay. https://www.bcu.gub.uy/
}

Práxis Educativa, Ponta Grossa, v. 15, e2015446, p. 1-24, 2020 Disponível em: < https://www.revistas2.uepg.br/index.php/praxiseducativa> 
institución, así como de la Fundación del mismo nombre, a partir de la cual fue generada. Allí señalábamos que esta Fundación fue creada por un conjunto de destacados representantes del pensamiento neoliberal y conservador en Uruguay. Formaban parte de la primera Comisión de la Directiva de la Fundación el ex canciller del gobierno de derechas instalado el 1 de marzo, Ernesto Talvi, así como el también el actual Ministro de Educación y Cultura, Pablo Da Silviera. En el caso de Talvi es necesario destacar su tarea entre los años 1997 y 2018 como director académico del Centro de Estudios de la Realidad Económica y Social (CERES). CERES es uno de los socios en Uruguay de la Atlas Economic Research Foundation, una organización dedicada a formar liderazgos y uno de los principales think thank ultraliberales o "libertaristas" de los Estados Unidos. La relación de CERES con la Fundación Atlas puede verificarse en la página web de esta última ${ }^{13}$. En el caso de Da Silviera se trata de un destacado académico vinculado a la Universidad Católica del Uruguay y que tiene una profusa producción en la que aboga por soluciones de mercado para los problemas que entiende tiene la educación en Uruguay (SILVIERA, 1995).

Otro de los integrantes relevantes de la dirección de la Fundación Impulso es el Dr. Nicolás Herrera, destacado actor de la economía uruguaya y que cuenta entre sus méritos más destacados el ser miembro de la Sociedad de Mont Pelerin, ícono del pensamiento neoliberal fundada en 1947 por Friederich Von Hayek y Ludwig Von Mises. Talvi, Da Silveira y Herrera constituyen actores claves en la construcción a nivel ideológico del discurso conservador en la educación uruguaya.

El objetivo fundamental que la Fundación Impulso se propone al generar el Liceo Impulso puede apreciarse en su sitio web. Allí se señala que los creadores de la Fundación,

$[\ldots]$ a título personal deciden tratar de desarrollar un instituto de enseñanza de ciclo
básico $\left(1^{\circ}\right.$ a $3^{\circ}$ de liceo que ya se extendió a $6^{\circ}$ año e incluso a un Bachillerato Vespertino
incluyendo una opción Tecnológica de Informática), de tiempo completo, laico, gratuito
y de gestión privada en una zona de contexto crítico para procurar contribuir a eliminar
la brecha de aprendizaje ${ }^{14}$.

En la breve cita pueden ya comprenderse las intencionalidades que están en juego. El liceo se ubica en Casavalle, uno de los barrios más pobres de la ciudad de Montevideo. Su ubicación allí radica en que lo que se pretende es atacar la llamada "brecha de aprendizaje", existente entre niños ya adolescentes pertenecientes a diversos contextos sociales y culturales. En términos de construcción discursiva, el establecimiento del Liceo Impulso en pleno barrio Casavalle ofrece las condiciones materiales para sostener las bondades de una educación gestionada por actores privados a partir de una asignación mediada por empresas de fondos públicos.

A los efectos de avanzar en esta dirección, el Liceo Impulso ingresa en el año 2011 en el procedimiento de Donaciones Especiales. En ese marco logra captar en el primer año un total de 12,1 millones de pesos. Su captación de recursos se amplía progresivamente, recibiendo, en el año 2018, un total de 73.1 millones de pesos. El incremento es del 604\%, muy superior al $490 \%$ que fue el porcentaje de crecimiento global de las donaciones en el período. Estamos, por tanto, frente al caso de una institución administrada por privados que recibe una muy importante suma de recursos por parte de empresas privadas, los cuales son, en buena medida, aportados por el Estado. Se cierra así el círculo de un proceso de privatización exógena financiada indirectamente por recursos estatales.

Es importante destacar que este direccionamiento de recursos de ningún modo puede entenderse como un fenómeno casual o aleatorio. El Liceo Impulso es concebido por sectores de

\footnotetext{
13 Ver https://www.atlasnetwork.org/partners/global-directory/centro-de-estudios-de-la-realidad-economica-ysocial

${ }^{14}$ Tomado de http://www.liceoimpulso.edu.uy/fundacion.
} 
la derecha uruguaya vinculadas a perspectivas conservadoras y neoliberales como el ejemplo modélico que debe mostrar la primacía de la gestión privada sobre la pública en términos de transformación educativa. Por lo tanto, aquí precisamente layase material desde el cual se sostiene una renovada discursividad conservadora en la educación uruguaya.

Una vez más, resulta relevante señalar que la misión fundamental desde la que se concibe la generación del Liceo Impulso es la de incidir en la eliminación de la brecha de aprendizajes, que se genera entre sectores ubicados en posiciones disímiles en la distribución de bienes materiales y culturales en la sociedad uruguaya. Ciertamente, el problema sobre el que se pretende incidir existe y es de entidad. Una aproximación a la problemática puede realizarse a partir de la observación del siguiente gráfico.

\section{Grafico 1}

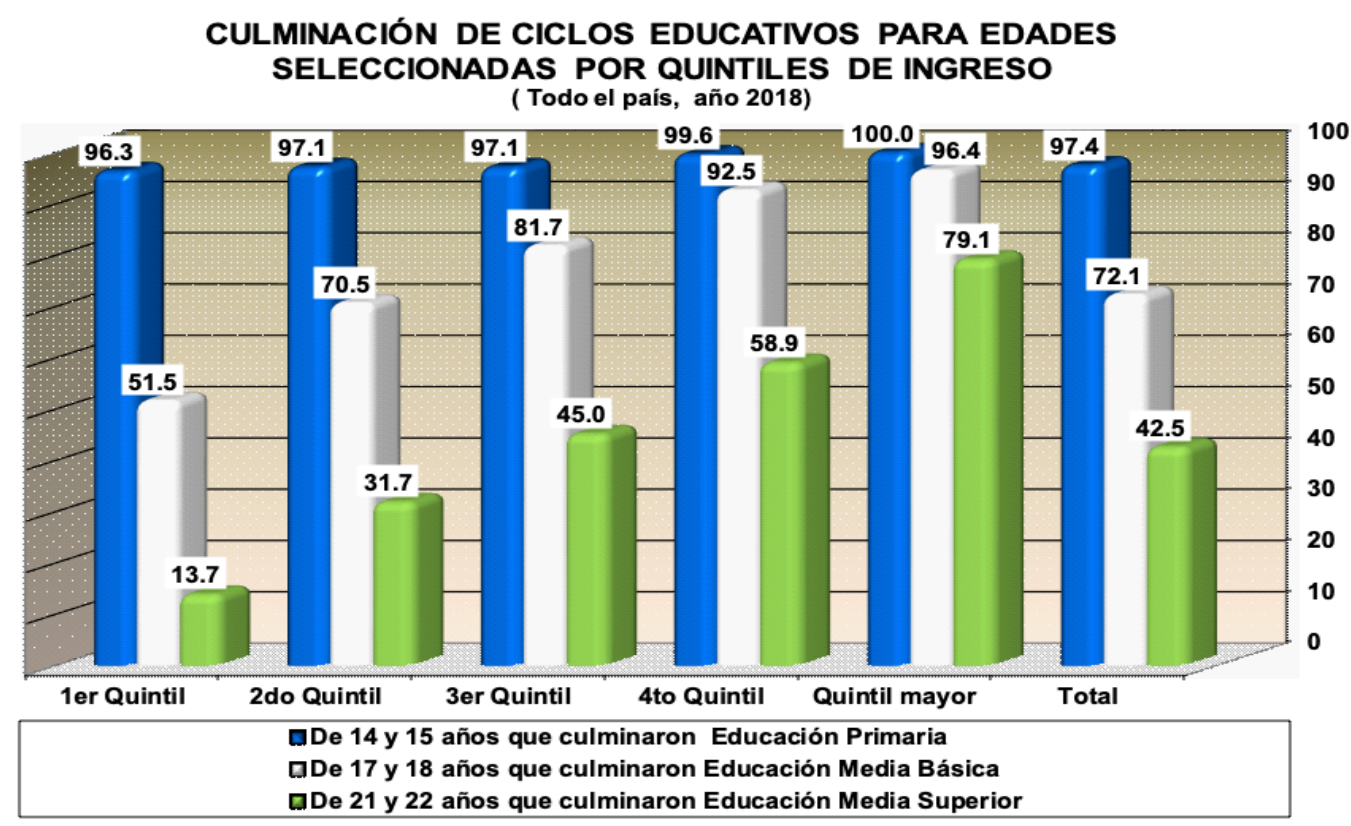

Fuente: Tomado de URUGUAY (2018).

La diferencia en cuanto a la finalización de ciclos educativos, según el quintil de ingresos al que pertenece, es claramente importante en Uruguay, particularmente a partir de la Enseñanza Media, que es el ámbito en el cual se ubica el Liceo Impulso. Como puede apreciarse: el 97,4 de los jóvenes de 17 y 18 años culminan la Enseñanza Media en el quintil más rico, mientras que solamente el 51,5 lo hacen en el quintil más pobre de la población.

Por tanto, la elección del barrio Casavalle como sede de la institución tampoco es casual. Según un análisis de información contenida en el Censo de 2011 (CALVO, 2013), Casavalle es el barrio que presenta mayores índices de necesidades básicas insatisfechas (NBI) en la ciudad de Montevideo, ya que en aquel año -el mismo en el que se comenzó a gestar el Liceo Impulso-, el $60,1 \%$ de sus habitantes tenían al menos una NBI. Este dato se realza en su contenido, si se tiene en cuenta que el promedio de población con al menos una NBI en Montevideo es de 26,8\%, siendo además el más bajo de todo el país.

En definitiva, no cabe duda que, teniendo en cuenta los objetivos que persigue, la Fundación Impulso eligió muy adecuadamente el medio en el cual insertar su institución educativa.

Con respecto al proyecto educativo que desarrolla el Liceo Impulso, retomamos algunas 
consideraciones incluidas en un trabajo ya citado:

En el caso del Liceo Impulso hemos podido constatar a través de análisis de información disponible en la página web y de una visita a la propia institución, el énfasis que se coloca en la superación de la "brecha de aprendizajes" se constituye desde una apelación al esfuerzo personal y a la construcción de la felicidad individual. De este modo, la forma de superar la situación de vulnerabilidad social que se presenta a los educandos por el hecho de desarrollar su existencia en un contexto surcado por desigualdades económicas y sociales, remite exclusivamente al mérito individual. Esto implica la necesidad de diferenciarse del entorno para lograr trascender en términos sociales. En este sentido, la propuesta educativa es definida como de "tiempo completo", abarcando un horario que se extiende de lunes a viernes de 8 a 17:10 h y los sábados de 8 a 12 h (MARTINIS, 2019, p. 328).

Lo señalado puede apreciarse con claridad retomando enunciados presentes en el propio sitio web de la institución. Bajo el título "Nuestra propuesta", puede leerse:

Somos un liceo gratuito, laico y de gestión privada, que desarrolla al máximo la potencialidad de sus alumnos con el máximo de exigencia, orientado a generar oportunidades para la búsqueda del desarrollo personal y la excelencia académica, basado en los valores de auto-respeto, ejercicio responsable de la libertad, disciplina y cultura del esfuerzo $^{15}$.

Por otra parte, bajo el título "Nuestros valores", se expresa:

Impulsar significa estimular; promover una acción. Es también la fuerza que lleva un cuerpo en movimiento o en crecimiento. De eso se trata nuestro modelo educativo. Es posible eliminar la brecha de aprendizaje que hay entre nuestros alumnos y los alumnos de los mejores liceos del país, públicos y privados.

En lo individual, promovemos la búsqueda de la felicidad, la realización personal, y la formación del carácter/de la personalidad. Cada uno de nosotros debe procurar ser, en la vida, productivo, útil a los demás, no sólo a su entorno familiar, sino más allá en la sociedad. Estamos seguros que en la búsqueda de la felicidad individual, única para cada persona, totalmente individual, el sentirnos útiles, valiosos, reconocidos por nuestros esfuerzos, talentos y virtudes, es un objetivo fundamental.

Sin una buena educación el camino de la realización personal se hace mucho más difícil. Pero esa educación no es suficiente. Se debe además educar la personalidad, el carácter como el conjunto de características y habilidades que hacen posible desarrollar el máximo potencial de la persona. Ellas son por ejemplo: el auto control, la fortaleza para superar obstáculos, el optimismo, el ser agradecido, la curiosidad, y la honestidad, entre otros.

Incluye el programa de valores una fuerte apuesta a la construcción del proyecto de vida personal y desarrollar el liderazgo como conducción de la propia vida ${ }^{16}$.

Si hemos introducido estas dos citas, la segunda de ellas ciertamente extensa, es porque entendemos que expresan con meridiana claridad los elementos que presentábamos en nuestro análisis previo. El énfasis en la potenciación de las capacidades individuales de cada quien, su apelación al carácter individual de la felicidad y la idea implícita de que la superación en términos educativos y sociales ha de lograrse exclusivamente en base a esfuerzos individuales, delinean un perfil ideológico en el que es posible apreciar la articulación de componentes neoliberales y conservadores. Este perfil se constituye en antagónico al tradicional de la educación uruguaya, sostenido sobre la base de la cooperación y en un ideal de igualdad social.

\footnotetext{
15 Tomado de: http://www.liceoimpulso.edu.uy/reservations

16 Tomado de: http://www.liceoimpulso.edu.uy/fundacion
}

Práxis Educativa, Ponta Grossa, v. 15, e2015446, p. 1-24, 2020 Disponível em: < https://www.revistas2.uepg.br/index.php/praxiseducativa> 
La construcción del modelo educativo que se concibe desde el Liceo Impulso, con estas apelaciones centradas fuertemente en sus logros sobre los individuos, se legitima mediante los resultados de aprendizaje que ostenta la institución con relación a las instituciones educativas públicas ubicadas en la misma zona. Cada año Impulso presenta sus "Memorias Anuales" en las que, además de una descripción de las actividades desarrolladas en ese ciclo, se presentan estudios comparativos de resultados de aprendizajes entre el Liceo y otros institutos públicos de la misma zona y de otros espacios del país. En la Memoria Anual del 2018, la más reciente a la que se tiene acceso por la web, se observan tablas como la que presentamos a continuación.

\section{Tabla 4}

PORCENTAJE DE ESTUDIANTES PROMOVIDOS POR CENTRO (EN DISTRITO ZONAL) Y COMPARACIÓN DE PROMOCIÓN 2017-2018 LICEO IMPULSO

\begin{tabular}{|c|c|c|c|c|c|c|}
\hline $\begin{array}{l}\text { Datos de } \\
\text { promoción }\end{array}$ & \begin{tabular}{|c|} 
CENTRO \\
A del \\
distrito \\
zonal \\
\end{tabular} & $\begin{array}{c}{ }^{*} \text { CENTRO } \\
\text { B del } \\
\text { distrito } \\
\text { zonal } \\
\end{array}$ & $\begin{array}{l}\text { "PROMEDIO } \\
\text { NACIONAL }\end{array}$ & $\begin{array}{l}\text { "PROMEDIO } \\
\text { DEPARTA" } \\
\text { MENTAL }\end{array}$ & \begin{tabular}{|c} 
LICEO \\
IMPULSO \\
2017
\end{tabular} & \begin{tabular}{|c} 
LICEO \\
IMPULSO \\
2018
\end{tabular} \\
\hline 1er año & $9,1 \%$ & $61,4 \%$ & $75,1 \%$ & $65,3 \%$ & $98,1 \%$ & $92 \%$ \\
\hline $\begin{array}{l}\text { Datos de } \\
\text { promoción }\end{array}$ & $\begin{array}{c}{ }^{*} \text { CENTRO } \\
\text { A del } \\
\text { distrito } \\
\text { zonal } \\
\end{array}$ & $\begin{array}{c}{ }^{*} \text { CENTRO } \\
\text { B del } \\
\text { distrito } \\
\text { zonal } \\
\end{array}$ & $\begin{array}{l}\text { "PROMEDIO } \\
\text { NACIONAL }\end{array}$ & $\begin{array}{l}\text { "PROMEDIO } \\
\text { DEPARTA- } \\
\text { MENTAL }\end{array}$ & \begin{tabular}{|c|} 
LICEO \\
IMPULSO \\
\\
2017 \\
\end{tabular} & $\begin{array}{c}\text { LICEO } \\
\text { IMPULSO } \\
2018\end{array}$ \\
\hline 2 do año & $50,6 \%$ & $59 \%$ & $76,8 \%$ & $67,7 \%$ & $96,1 \%$ & $93 \%$ \\
\hline $\begin{array}{l}\text { Datos de } \\
\text { promoción }\end{array}$ & $\begin{array}{c}{ }^{*} \text { CENTRO } \\
\text { A del } \\
\text { distrito } \\
\text { zonal } \\
\end{array}$ & $\begin{array}{c}{ }^{*} \text { CENTRO } \\
\text { B del } \\
\text { distrito } \\
\text { zonal } \\
\end{array}$ & $\begin{array}{l}\text { "PROMEDIO } \\
\text { NACIONAL }\end{array}$ & $\begin{array}{l}\text { "PROMEDIO } \\
\text { DEPARTA- } \\
\text { MENTAL }\end{array}$ & \begin{tabular}{|c|} 
LICEO \\
IMPULSO \\
\\
2017 \\
\end{tabular} & $\begin{array}{c}\text { LICEO } \\
\text { IMPULSO } \\
2018\end{array}$ \\
\hline 3er año & $52,5 \%$ & $59,2 \%$ & $74 \%$ & $66,9 \%$ & $75,3 \%$ & $89 \%$ \\
\hline
\end{tabular}

•Datos obtenidos de Monitor educativo Liceal año 2017, los datos 2018 aún no se han publicado.

Fuente: Tomada del sitio web del Liceo Impulso ${ }^{17}$.

Como puede apreciarse, el Liceo Impulso sale favorecido en todas las comparaciones que se presentan. A partir de la sistematización de datos de este tipo, profusamente reproducidos por los medios de comunicación, se logra establecer el principio de que la educación "pública de gestión privada" presenta características más adecuadas al trabajo en estos contextos educativos que los que aporta la educación pública. Este principio circula en términos de la construcción de un sentido

\footnotetext{
17 Tomado de: https://static1.squarespace.com/static/5798f0119de4bb07b7c88794/t/5d41e16018fdf300018bc548/156459866182 3/Memoria+Anual+2018
}

Práxis Educativa, Ponta Grossa, v. 15, e2015446, p. 1-24, 2020 Disponível em: < https://www.revistas2.uepg.br/index.php/praxiseducativa> 
común sobre la educación en la sociedad uruguaya. Este sentido común llega a ser asumido por actores vinculados a sectores progresistas, tradicionalmente defensores de la educación pública. Aquí queda exhibida su potencialidad hegemónica, en tanto logra captar actores sociales previamente adheridos a la centralidad de la educación y reacios a aceptar mayores niveles de involucramiento de agentes privados.

No obstante, resulta necesario realizar algunas consideraciones con respecto a las condiciones materiales sobre las que reposa el desarrollo del Liceo Impulso. Nos detendremos aquí en dos aspectos: sus formas de selección del alumnado y los montos de financiamiento a partir de los cuales se sustentan sus actividades.

Con relación al primer tópico, es importante señalar que la institución no realiza una selección explícita de los alumnos que acceden a sus cursos, ya que se desarrolla un sorteo entre todos los postulantes de la zona que se inscriban. El punto clave para comprender como se excluye una categoría de potenciales alumnos, es que no se aceptan inscripciones para ese sorteo de adolescentes que hayan repetido de grado más de dos veces en su escolaridad previa. De esta manera, quedan fuera de la posibilidad de acceder a la institución quienes a priori es posible conjeturar que tendrían más dificultades para aprobar los cursos.

Respecto a los montos de financiamiento que maneja la institución, ya señalamos el carácter significativo de los recursos a los que accede mediante la modalidad de "donaciones especiales". Este punto debe complementarse con un estudio del financiamiento con el que se dispone en relación con el que posee una institución educativa púbica del mismo nivel. En este sentido, es interesante tener en cuenta que:

Desde 2015 (primer año con que se cuenta información del balance en la rendición de cuentas), por cada peso por estudiante que gasta el $\mathrm{CES}^{18}$, el Impulso gastó \$2,63 en 2015; \$2,2 en 2016; y \$ 2 en 2017. (DUFRECHOU; et al., 2019, p. 110).

Como puede apreciarse, la institución dispone de un presupuesto que al menos duplica el disponible en la enseñanza pública. Si a esto le sumamos el hecho que implementa una sutil forma de excluir a los alumnos potencialmente más desaventajados, se podrá concluir sin demasiada dificultad que la comparación con los resultados educativos de las instituciones públicas es al menos engañosa.

En definitiva, nos encontramos frente a una institución que es presentada como modélica en cuanto a los resultados que obtiene y como alternativa frente a lo que se define como el fracaso de la educación pública en contextos de pobreza. Esta caracterización hace que se la conciba como un espacio de diferenciación social para los jóvenes que acceden a matricularse en ella, generándose un modelo de distinción con respecto al resto de los jóvenes de la zona. Para quienes acceden a matricularse, la institución es presentada como la encarnación de una forma de salvación frente al resto de los estudiantes de la zona que están "condenados" a la educación pública.

Finalmente, cabe destacar que esta institución es presentada como experiencia a replicar en la propuesta de instalar 136 "liceos modelo" que en 2016 realizara el Centro de Estudios de la Realidad Económica y Social. Como señaló en una entrevista a un medio de prensa en el año 2016 Ernesto Talvi, en ese momento director del CERES:

Si nos quedamos fuera de la revolución económica del siglo XXI y no preparamos a las generaciones jóvenes para tener las destrezas que les van a permitir insertarse en esa

\footnotetext{
${ }^{18}$ La sigla hace referencia al Consejo de Enseñanza Secundaria, organismo responsable del nivel de Educación Secundaria, Básica y Superior en Uruguay.
} 
El progresivo avance de perspectivas conservadoras en la educación uruguaya en la última década

economía, nos vamos a ir atrasando como país porque a nadie le va a interesar venir a invertir acá si no está el capital humano necesario", advierte Talvi. El director de Ceres admira al liceo Impulso. "Ha cambiado la vida de los chicos, de las familias y de la comunidad que estaba 'guetizada' y deprimida. Solo 5\% de los chicos concebían la idea de tener estudios después de terminar el liceo. Hoy 85 de cada 100 piensan en ser profesionales. Tienen 10 horas de clase por día, tres comidas, tienen atención sanitaria permanente, están bien alimentados ${ }^{19}$.

De la consideración de esta nota de prensa se extrae claramente la relación existente la experiencia del Liceo Impulso y la propuesta de crear 136 "liceos modelos", basados en esa experiencia. Este dato resulta relevante ya que, luego, esa propuesta es traslada al programa de gobierno del Partido Colorado cuando el propio Talvi es elegido como candidato a la presidencia del mencionado partido tradicional de Uruguay, en 2019.

En el sitio web oficial, desde el que se promovió la candidatura de Talvi, puede leerse:

\section{¿Quiénes irían a los liceos públicos modelo?}

Identificamos a los jóvenes de los contextos vulnerables en edad de asistir a los liceos públicos modelo. Son aquellos que entre 2020 y 2026 tendrían edad para ingresar en la educación media. En total, 80 mil jóvenes en edad liceal viven en zonas consideradas de alta vulnerabilidad. Entre ellos, 40 mil residen en el Área Metropolitana de Montevideo y 40 mil en el interior urbano.

Una vez identificada la población objetivo y su ubicación, calculamos cuántos liceos públicos modelo corresponden a cada localidad. Para esto, es necesario tomar en cuenta: la cantidad de jóvenes en edad liceal en los contextos vulnerables de la localidad, el tamaño de estos liceos (100 alumnos por grado para un total de 600) y si la localidad es la capital departamental. El total de liceos modelo necesarios es $136^{20}$.

Como puede apreciarse, la propuesta es la misma que la originalmente lanzada por CERES a partir de la experiencia del Liceo Impulso.

Luego de realizada la primera vuelta de la elección presidencial en Uruguay, en la que el partido de Talvi obtuvo la tercera posición, se conformó una coalición que agrupó a partidos de centro y derecha. Este se presentó como alternativa al Frente Amplio gobernante y respaldó la candidatura a la presidencia del candidato del Partido Nacional Luis Lacalle Pou. Esta coalición unió tras la candidatura de Lacalle a los partidos Nacional, Colorado ${ }^{21}$, Cabildo Abierto ${ }^{22}$, de la Gente $^{23}$ e Independiente ${ }^{24}$. Esta coalición acordó un programa común de gobierno previo a la realización del ballotage que definiría la elección presidencial. Este programa de gobierno se presentó bajo el título "Compromiso por el País". En el capítulo 8 del mencionado documento, titulado "Transformar la Educación", puede leerse el objetivo de desarrollar un: "Plan de instalación de centros modelo de Educación Media en barrios vulnerables de todo el país, que

\footnotetext{
${ }^{19}$ Diario El País. Una iniciativa para crear 136 liceos con un horario extendido. Montevideo, 12 de junio de 2016.

20 Tomado de https:/ / talvi.uy

${ }^{21}$ Los Partidos "Nacional” y "Colorado" son dos partidos tradicionales históricos de Uruguay. Entre ambos gobernaron el país entre 1830 y 2004, con la sola interrupción producida por la dictadura militar que se extendió de 1973 a 1984.

22 Partido de extrema derecha formado seis meses antes de las elecciones y que llevó como candidato a la Presidencia a un ex comandante en jefe del Ejército. Se ubicó como la cuarta fuerza política del país.

${ }^{23}$ Partido de derecha con cinco años de existencia y nucleado en torno a un poderoso empresario del rubro del comercio. Tuvo escasa votación.

${ }^{24}$ Partido de centro integrado por ex adherentes del Frente Amplio. Tuvo una votación nominal.
}

Práxis Educativa, Ponta Grossa, v. 15, e2015446, p. 1-24, 2020

Disponível em: < https://www.revistas2.uepg.br/index.php/praxiseducativa> 
funcionarán en el marco de una nueva modalidad educativa de la ANEP’25.

Si bien no se mantiene la cuantificación de 136 liceos, puede apreciarse que la apelación al establecimiento de centros educativos "modelo" se mantiene, haciendo referencia a la misma idea.

Es interesante apreciar cómo una experiencia desarrollada a partir de un Think Tank neoliberal local, financiado profusamente con fondos provenientes de empresas privadas, que luego recuperan una porción significativa de éstos por medio de exoneraciones fiscales, consigue colocarse como base de la transformación educativa que impulsa el gobierno conservador actualmente en ejercicio en Uruguay ${ }^{26}$.

Por otra parte, resulta fundamental para el enfoque que orienta nuestra investigación, tomar nota de cómo, a partir del fomento de una forma de privatización exógena caracterizada por el financiamiento público indirecto de experiencias privadas, se colocan las bases para sustentar la transformación de la propia educación pública. En otros términos, se trata de comprender cómo una forma de privatización exógena funciona como base para justificar la implementación de formas endógenas de privatización. Esto es: la asunción de lógicas de gestión privadas dentro de las propias instituciones de la educación pública.

Estas formas de privatización endógena constituyen el punto de llegada de la posición contrahegemónica tan pacientemente construida por la derecha uruguaya: desmontar la centralidad de la educación pública introduciendo, en su propio seno, formas de gestión propias del ámbito privado.

\section{Conclusiones. El impulso a un discurso conservador en la educación uruguaya}

En el presente artículo hemos presentado algunas características estructurales del sistema educativo uruguayo vinculadas, particularmente, con la histórica construcción de la educación pública desde una posición hegemónica y con el subsiguiente espacio subsidiario ocupado por la educación privada. Esta ha sido una de las características que ha distinguido al sistema educativo uruguayo desde su constitución como tal, en el último tercio del siglo XIX (URUGUAY, 2014). De todos modos, este lugar secundario ocupado por la educación privada no ha sido impedimento para que, en diversos contextos históricos, se consiguiera introducir en la Constitución Nacional artículos que salvaguardan sus posiciones y le otorgan exoneraciones fiscales como subvención por sus aportes a la educación.

Por otra parte, hemos plateado que durante la denominada era progresista (2005 - 2019) se produjeron avances en cuanto a la ubicación de la educación como un derecho humano y un bien público y social. Desde aquí, se consolidó el carácter rector de la educación pública, reforzando el lugar del Estado como garante del derecho a la educación de la población en su conjunto. Este período podría ser definido, simultánea y contradictoriamente, como el de la consolidación de una práctica hegemónica basada en la centralidad de la educación pública y el de comienzo de una construcción conservadora con afán contrahegemónico.

De esta manera, las diversas perspectivas existentes en el campo progresista en torno a los medios adecuados para satisfacer el derecho a la educación, supusieron el establecimiento de condiciones para que paulatinamente fueran tomando fuerza posiciones conservadoras que se

\footnotetext{
25 Tomado de https://lacallepou.uy/compromiso.pdf.

${ }^{26}$ De hecho medidas tendientes a hacer posible la instalación de este tipo de centros educativos se encuentran contempladas en una propuesta legislativa actualmente a consideración del Poder Legislativo uruguayo.
} 
El progresivo avance de perspectivas conservadoras en la educación uruguaya en la última década

propusieron disputar el lugar hegemónico de la educación pública.

Esta disputa, que los sectores conservadores consiguieron ubicar con respecto a la centralidad de la educación pública, supuso una forma de reactualización de la lógica inherentemente conflictiva (MOUFFE, 2007) que define a la política y a la cual nos referimos en el primer apartado del presente texto. Es probable que los sectores progresistas, absorbidos en llevar adelante la gestión del sistema educativo, hayan descuidado la arena propiamente política, esto es, el lugar del conflicto y la disputa. Asumieron así una posición de cuño liberal, caracterizada por la actuación de actores "pertenecientes al campo progresista, (que) aceptan esta visión optimista de la globalización, y han pasado a ser los defensores de una forma consensual de democracia" (MOUFFE, 2009, p. 9). Mouffe define a esta posición como "pospolítica" en tanto renuncia a la definición del conflicto como práctica específicamente política y asume que es posible lograr consensos y acuerdos entre quienes ocupan posiciones antagónicas. Si estamos en lo cierto, la pérdida de centralidad hegemónica de la educación pública en la sociedad uruguaya tendría vínculo con estas formas de negación de la política asumidas por los sectores progresistas.

La disputa se vehiculizó a través de una insistente presentación por parte de los sectores conservadores del significante crisis educativa como forma de definir la realidad de la educación generada en los gobiernos progresistas. La paulatina instalación de la noción de crisis como forma de definir a la educación progresista permitió que discursos de matrices tanto conservadoras como neoliberales fueran ocupando progresivamente espacios de reconocimiento en la sociedad uruguaya.

A partir de la utilización de una modalidad aprobada en los gobiernos progresistas denominada "donaciones especiales", se generó una institución educativa referenciada como modelo para la intervención sobre la "brecha educativa", definida por los resultados desiguales que obtienen estudiantes provenientes de diversos contextos sociales y económicos. De hecho, la alternativa conservadora se construye precisamente por medio del desarrollo de una intervención educativa "exitosa" en los contextos de mayor pobreza de la ciudad de Montevideo.

La modalidad de "donaciones especiales" permite el tránsito de recursos desde empresas privadas ${ }^{27}$ hacia instituciones "públicas de gestión privada", a costa de renuncias fiscales por parte del Estado. Mediante esta modalidad se logra, desde una lógica conservadora, disputar al mismo tiempo el carácter público de la educación, la construcción de políticas educativas y su financiamiento.

Las discursividades conservadoras y neoliberales encontraron una fuerte convergencia en la definición de la "educación pública de gestión privada" como alternativa para la fallida educación pública. Uno de los elementos claves en los que podrá apreciarse esta convergencia es en la ubicación del individuo como objetivo prioritario y destinatario de la educación. Desestructurar las apelaciones a lo colectivo y al reconocimiento de las desigualdades sociales, propias de un discurso pedagógico progresista fue, sin duda, uno de los éxitos de estas perspectivas emergentes. El énfasis en el desarrollo particular de cada individuo como aspecto central de un proyecto educativo vino a reactualizar las lógicas de la competencia y de la responsabilidad individual, por éxitos y fracasos, que habían sido opacadas por el progresismo pedagógico. Este, indudablemente, constituyó una de las significaciones centrales expuestas por el renovado discurso conservador en la educación uruguaya.

\footnotetext{
${ }^{27}$ En un trabajo de investigación complementario al que aquí presentamos nos encontramos trabajando en una caracterización de estas empresas donantes desde el punto de vista de su ubicación en el mapa de poder económico y político de la sociedad uruguaya.
}

Práxis Educativa, Ponta Grossa, v. 15, e2015446, p. 1-24, 2020 Disponível em: < https://www.revistas2.uepg.br/index.php/praxiseducativa> 
Los sentidos sobre la educación aquí abordados configuran la propuesta educativa de la coalición de derechas que, desde el 1 de marzo de 2020, se encuentra gobernando en Uruguay. La estrategia que ésta ha desarrollado, desde mucho antes de su triunfo en las urnas, articula de modo no siempre directo actores económicos, políticos, sociales, técnicos y religiosos. Las propuestas conservadoras, que durante las últimas décadas se estuvieron generando y articulando, están en las base de las orientaciones de gobierno de la coalición que ha asumido el gobierno. Como hemos visto, estas propuestas surgieron y fueron promovidas apelando a formas de privatización exógenas y hoy son la base para la promoción de formas de privatización endógenas.

A partir del desarrollo de estas nuevas propuestas, se abre un amplio campo para la investigación sobre educación ocupada en analizar las manifestaciones que asume, a nivel conceptual y también en la práctica, una educación concebida desde las nuevas derechas (BORDOLI; CONDE, 2020). Los procesos producidos en buena parte de América Latina aportan referencias contextuales y conceptuales para el análisis de los nuevos fenómenos en curso en Uruguay. Sobre estos fenómenos es necesario y urgente continuar avanzando en trabajos de investigación.

\section{Bibliografía referida}

ADRIÃO, T.; PERONI, V. Público e privado na educação: novos elementos para o debate. São Paulo: Xama, 2008.

BELLEI, C. E1 gran experimento. Mercado y privatización de la educación chilena. Santiago: LOM, 2015.

BENTANCUR, N. Las reformas educativas de los noventa en Argentina. Chile y Uruguay: racionalidad política, impactos y legados para la agenda actual. Montevideo: Ediciones de la Banda Oriental, 2008.

BORDOLI, E. Formas escolares y sentidos educativos en Enseñanza Primaria. Análisis del proceso de construcción del Programa Maestros Comunitarios en Uruguay (2005-2010). Montevideo: Universidad de la República, 2019.

BORDOLI, E.; CONDE, S. El proyecto educativo conservador en Uruguay en los albores del siglo XXI: avance privatizador y tutela ministerial. Práxis Educativa, Ponta Grossa, v. 15, e2015343, p. 1-21, 2020. DOI: https://doi.org/10.5212/PraxEduc.v.15.15343.084

BORDOLI, E.; MARTINIS, P.; MOSCHETTI, M.; CONDE, S.; ALFONZO, M. Privatización educativa en Uruguay: Políticas, actores y posiciones. Montevideo: Internacional de la Educación, 2017.

BORDOLI, E.; MARTÍNEZ, M.; MARTINIS, P.; MOSCHETTI, M. The increasing role of nonState actors in education policy-making. Evidence from Uruguay. Journal of Education Policy, v. 35, n. 3, p. 367-393, 2020. DOI: https://doi.org/10.1080/02680939.2018.1562569

BENTANCUR, N.; BUSQUETS, J. The Governing Left in Uruguay (2005-2015): Analysis of a Participatory Democratic Experiment. Latin American Perspectives, v. 46, n. 1, p. 137-151, 2019. DOI: https://doi.org/10.1177/0094582x18807488

CALVO, J (coord.). Atlas sociodemográfico del Uruguay. Fascículo 1: Las necesidades básicas insatisfechas a partir de los Censos 2011. Montevideo: Trilce, 2013. 
El progresivo avance de perspectivas conservadoras en la educación uruguaya en la última década

FERNÁNDEZ, T. Políticas de inclusión en la Educación Básica de Uruguay (2005-2015). Montevideo: Universidad de la República, 2018.

DUFRECHOU, H.; et al. El avance privatizador en la educación uruguaya: discursos y políticas. Montevideo: Internacional de la Educación, 2019.

GARCÉ, A.; YAFFÉ, J. La era progresista. Montevideo: Fin de Siglo, 2005.

HALL, S. La educación en crisis. Revista de Educación, n. 283, p. 29-35, mayo/ago. 1987.

HOWARTH, D. "Aplicando la Teoría del Discurso: el Método de la Articulación”. Studia Politicae, n. 5, ed. otoño, 2005. Córdoba: Editorial Universidad Católica de Córdoba, 2005.

LACLAU, E. La imposibilidad de la sociedad. In: LACLAU, E. Nuevas reflexiones sobre la revolución de nuestro tiempo. Buenos Aires: Verso, 1993. p. 103-106.

LACLAU, E.; MOUFFE, C. Hegemonía y estrategia socialista. Hacia una radicalización de la democracia. Buenos Aires: Fondo de Cultura Económica, 2004.

LEHER, R. Políticas de privatización, espacio público y privatización en América Latina. Rosario: CLACSO/Homosapiens Editores, 2009.

MANCEBO, M.; CARNEIRO, F.; LIZBONA, A. La educación: ¿un 'outsider' de la protección social?: un análisis a partir de las políticas de inclusión educativa en Uruguay 2005-2013. Psicología, Conocimiento y Sociedad, v. 4, n. 2, p. 295-323, nov. 2014.

MARTINIS, P. Tensiones y asuntos pendientes en relación con la cuestión docente en Uruguay. In: PERAZZA, R. Carreras docentes en América Latina. Perspectivas, conflictos y debates pendientes. Buenos Aires: Aique Educación, 2019a. p. 179-200.

MARTINIS, P. Modelos educativos privatizadores y disputas por el derecho a la educación. SERPAJ: Derechos humanos en el Uruguay. Informe 2019. Montevideo: Tradinco, 2019b.

MARTINIS, P.; FALKIN, C. Aspectos pedagógicos y de política educativa involucrados en los procesos de universalización del derecho a la educación. In: CRISTÓFORO, A.; MARTINIS, P.; MÍGUEZ, M.; VISCARDI, N. (org.). Derecho a la educación y mandato de obligatoriedad en la enseñanza media. La igualdad en cuestión. Montevideo: Universidad de la República, 2017. p. 18-64.

MARTINIS, P. Aproximación a los usos del significante inclusión educativa en la formulación de políticas educativas en Uruguay (2005 2015). In: MARTIGNONI, L.; ZELAYA, M. (org.). Diálogos entre Argentina, Brasil y Uruguay. Sujetos, políticas y organizaciones en educación. Buenos Aires: Biblos, 2016. p. 245-261.

MOSCHETTTI, M.; MARTÍNEZ PONS, M.; BORDOLI, E.; MARTINIS, P. The increasing role of non-State actors in education policy-making. Evidence from Uruguay. Journal of Education Policy, v. 35, n. 3, p. 367-393, 2019. DOI: https://doi.org/10.1080/02680939.2018.1562569

MOUFFE, C. En torno a lo político. Buenos Aires: Fondo de Cultura Económica, 2009.

MOUfFE, C. Agonística. Pensar el mundo políticamente. Buenos Aires: Fondo de Cultura Económica, 2014.

PERONI, V. Redefinições das fronteiras entre o público e o privado: implicações para a 
democratização da educação. Brasilia: Liber Livro, 2013.

PERONI, V.; DE LIMA, P.; KADER, C. Redefinições das fronteiras entre o público e o privado. Implicações para a democratização da educação. Sao Leopoldo: Oikos, 2018.

PUIGGRÓS, A. Sujetos, disciplina y currículum en los orígenes del sistema educativo argentino. Buenos Aires: Galerna, 1990.

RANCIÉRE, J. E1 Maestro ignorante. Cinco lecciones sobre la emancipación intelectual. Barcelona: Laertes, 2003.

SILVIERA, P. La segunda reforma. Montevideo: Fundación Bank Boston, 1995.

URUGUAY. Ministerio de Educación y Cultura (MEC). Ley General de Educación. Montevideo: Impresiones y Publicaciones Oficiales (IMPO), 2018.

URUGUAY. Ministerio de Educación y Cultura (MEC). A 140 años de la educación del pueblo: Aportes para la reflexión sobre la educación en el Uruguay. Montevideo: MEC, 2014.

VERGER, A.; MOSCHETTI, M.; FONTDEVILA, C. La privatización educativa en América Latina: Una cartografía de políticas, tendencias y trayectorias. Bruselas: Internacional de la Educación, 2017.

VIOR, S. Privatización de la educación: el caso argentino. In: PERONI, V.; DE LIMA, P.; KADER, C. Redefinições das fronteiras entre o público e o privado. Implicações para a democratização da educação. Sao Leopoldo: Oikos, 2018. p. 47-60.

\section{Fuentes consultadas}

ERNESTOTALVI, sitio web de su candidatura: https://talvi.uy.

Ley 15977. Disponible en:

https://legislativo.parlamento.gub.uy/temporales/leytemp2711093.htm

Ley 18083. Disponible en: https://legislativo.parlamento.gub.uy/temporales/leytemp615608.htm

Ley 18786. Disponible en:

https://legislativo.parlamento.gub.uy/temporales/leytemp8890149.htm

Ley 18834. Disponible en:

https://legislativo.parlamento.gub.uy/temporales/leytemp8170446.htm

Ley 19149. Disponible en:

https://legislativo.parlamento.gub.uy/temporales/leytemp5990099.htm

Ley 19438. Disponible en:

https://legislativo.parlamento.gub.uy/temporales/Ley194389703957.htm

Liceo Impulso, sitio web: http://www.liceoimpulso.edu.uy/fundacin

URUGUAY. Ministerio de Economía y Finanzas (MEF). Rendición de cuentas y balance de ejecución presupuestal. Ejercicio 2018. Exposición de motivos. Anexo 4.5 "Donaciones especiales con exoneraciones fiscales. 2018. 
URUGUAY. Ministerio de Educación y Cultura (MEC). Logro y nivel educativo de la población 2018. Montevideo: MEC, 2018.

URUGUAY. Ministerio de Educación y Cultura (MEC). Ley General de Educación. Montevideo: Impresiones y Publicaciones Oficiales (IMPO), 2008.

URUGUAY. Constitución de 1967 con las modificaciones plebiscitadas el 26 de noviembre de 1989, el 26 de noviembre de 1994, el 8 de diciembre de 1996 y el 31 de octubre de 2004. 1967. Disponible en: https://www.impo.com.uy/bases/constitucion/1967-1967. Acceso en: 8 set. 2020.

Recibido: $18 / 05 / 2020$

Versión corregida: $03 / 09 / 2020$

Aceptado: 04/09/2020

Publicado online: $10 / 09 / 2020$ 